NBER WORKING PAPER SERIES

\title{
THE QUALITY DISTRIBUTION OF JOBS AND THE STRUCTURE OF WAGES IN SEARCH EQUILIBRIUM
}

\author{
Steven J. Davis \\ Working Paper 8434 \\ http://www.nber.org/papers/w8434 \\ NATIONAL BUREAU OF ECONOMIC RESEARCH \\ 1050 Massachusetts Avenue \\ Cambridge, MA 02138 \\ August 2001
}

My early thinking on this project benefited from conversations with Arthur Hosios and Randy Wright. Participants at the Fourth Canadian Labour Conference in Toronto (May 1993), the NBER Summer Institute working group on "Micro and Macro Perspectives on the Labor Market" (July 1993) and seminar participants at Chicago, Wisconsin, and Illinois also provided many helpful comments. My discussants, Chris Pissarides and Tom Sargent, and other participants at a Stockholm conference (June 1995)in honor of Assar Lindbeck also provided many insightful comments. Manuel Cruzat provided able research assistance. The National Science Foundation and the Graduate School of Businesss at the University of Chicago provided research support. Available for download at http://gsbwww.uchicago.edu/fac/steven.davis/research. The views expressed herein are those of the author and not necessarily those of the National Bureau of Economic Research.

(C) 2001 by Steven J. Davis. All rights reserved. Short sections of text, not to exceed two paragraphs, may be quoted without explicit permission provided that full credit, including (C) notice, is given to the source. 
The Quality Distribution of Jobs and the Structure of Wages in Search Equilibrium Steven J. Davis

NBER Working Paper No. 8434

August 2001

JEL No. J31, J24, J64, E24

\begin{abstract}
$\underline{\text { ABSTRACT }}$
When match formation is costly and wage determination is decentralized, privately optimal investments in job and worker quality diverge from socially efficient outcomes. To explore this issue, I consider search equilibrium environments with endogenous quality distributions for jobs and workers. I show that a search equilibrium with decentralized wage setting exhibits excessive relative supplies of inferior jobs and inferior workers. Moreover, there are fundamental tensions between the standard wagesetting condition for an efficient total supply of jobs (and workers) in two-sided search models and the conditions required for efficient mixes of jobs and workers. I also derive the efficient wage structure, contrast its properties to the decentralized wage structure and evaluate the welfare and productivity gains of moving to an efficient wage structure. Numerical exercises show that centralized bargaining between a labor union and an employer confederation over the structure of wages can improve productivity and welfare by compressing job-related wage differentials.
\end{abstract}

Steven J. Davis

Graduate School of Business

University of Chicago

1101 East $58^{\text {th }}$ Street

Chicago, IL 60637

and NBER

Tel: (773) 702-7312

Fax: (773) 702-0458

Email: sjd@gsbsjd.uchicago.edu 


\section{Introduction}

The employment relationship between a firm and worker often gives rise to rents or quasi-rents. These rents may arise because it is costly to form a successful firm-worker match or because of specific investments undertaken by firm and worker after match formation. Alternatively, rents may derive from the firm's product market power, its ability to secure nonlabor inputs on favorable terms, or employer responses to effort elicitation and other incentive problems.

When the firm and worker make investment decisions that influence the amount of rents to be split, privately optimal choices potentially diverge from joint wealth-maximizing (or socially optimal) outcomes. Grout (1984) analyzes the prototypical situation of a firm and a union that bargain over employment and wages after the firm undertakes an investment with a sunk cost component. The firm, rationally anticipating that the union will extract some of the incremental quasi-rents generated by the investment, chooses less than the joint wealth-maximizing amount of investment. If the firm and union can enter into a binding agreement that specifies investment, as well as employment and wages, joint wealth-maximizing outcomes result.

The literature on specific capital in the employment relationship identifies contract enforcement and asymmetric information problems as important reasons for separation outcomes that fail to maximize joint wealth. ${ }^{1}$ The same contract enforcement and asymmetric information problems that induce inefficient separation behavior are also likely to induce inefficient investment in match-specific capital. Becker's (1975, pp. 26-37) discussion, for example, stresses the need for long-term contracts with an appropriate compensation

\footnotetext{
${ }^{1}$ Parsons (1986, especially pages 819-827) reviews this literature. Hall and Lazear (1984) catalog a variety of contracting arrangements that potentially achieve efficient separation behavior but are rendered infeasible by informational constraints.
} 
structure to achieve wealth-maximizing behavior with respect to separation decisions and specific human capital investment.

This paper analyzes a different, but related, reason for potentially inefficient investment outcomes. The analysis rests on two observations. First, trade in the labor market is a costly economic activity for both firms and workers. As remarked above, these costs imply the existence of ex post rents or surplus upon the formation of a desirable match between a firm and worker. Second, many of the investment decisions that influence the size of the ex post rents associated with a particular match take place prior to match formation.

As examples of these prior decisions, firms choose particular locations, they build facilities with certain characteristics, and they choose particular production processes. Individuals choose whether to participate in the labor market, whether and where to relocate, and whether to undergo specific training to improve their suitability for a particular job or type of job. In this paper, these prior investment decisions govern the quality distribution of jobs and the quality distribution of workers that emerge in the labor market equilibrium. Here, "job quality" means any attribute of a job that workers care about including productivity, working conditions, location, and so forth. Likewise, "worker quality" means any attribute of individuals that firms care about.

To capture the idea that match formation is costly, I cast the analysis in the framework of search theory. To capture the role of prior investment decisions, I assume that firms undertake costly job creation activities prior to forming a match with a worker. Section II develops a bare-bones model along these lines that illuminates the central insight in the paper. The analysis considers a one-period search model of the Diamond-MortensenPissarides variety. ${ }^{2}$ Firms and workers meet randomly according to a bilateral matching

${ }^{2}$ Diamond (1981,1982), Mortensen (1982ab), and Pissarides (1984, 1990) are some of the 
process and split the surplus associated with successful meetings according to a simple sharing rule. Unlike previous work in this vein, the model incorporates the costly creation of jobs that are heterogeneous ex ante.

The analysis reveals that the quality distribution of jobs is generally inefficient in the decentralized search equilibrium, with an excessive relative supply of inferior jobs. The analysis also highlights a fundamental tension between the condition for an efficient mix of jobs and the standard condition for an efficient total supply of jobs in two-sided search models. The tension arises from the mixing of heterogeneous jobs that are endogenously supplied to the search environment. This mixing feature is the key characteristic that distinguishes the search environments considered here from most other search models.

Section III extends the efficiency analysis of the job quality distribution in several directions. Section III.A considers endogenously determined search intensity on the part of firms and search costs that vary with job type. This environment leads to a modification of the relative supply efficiency condition, but it does not eliminate the basic tension between relative and total supply efficiency conditions. Section III.B shows that perfect ex ante sorting of heterogenous jobs into separate search markets does remove the tension between relative and total supply efficiency conditions. Section III.C extends the analysis to encompass endogenous quality determination on both sides of the market. It turns out that two-sided endogenous quality determination compounds the incompatibility of efficiency conditions in the search equilibrium with decentralized wage bargaining.

Section IV investigates whether there exists any wage structure that simultaneously achieves an efficient number and mix of jobs. The analysis provides an affirmative answer, shows that efficiency requires a uniform (expected) wage across jobs, and explains why this wage structure is unlikely to result from a decentralized wage determination process. When

principal references in this literature. 
the quality distribution is endogenous on both sides of the market, efficiency requires equal expected wages across jobs of different productivities (where the expectation is calculated over the distribution of worker types) and wages that fully reflect expected productivity differences that stem from worker traits. Relative to the efficient wage structure, decentralized wage bargaining entails too much compression of worker-related productivity differentials and too little compression of job-related productivity differentials.

Section $\mathrm{V}$ develops an analytical solution to the basic model with heterogeneous jobs and homeogeneous workers under isoelastic schedules for the cost of job creation. The analytical solution facilitates a quantitative analysis of the potential productivity and welfare consequences of alternative wage-setting regimes.

Section VI inquires into the nature of an optimal employment tax and and subsidy structure, i.e., an industrial policy, given that wages are determined by decentralized bargaining in the basic model. The analysis derives the structure of an optimal industrial policy and shows that this structure induces a spreading of wage differentials across jobs relative to the decentralized equilibrium with no industrial policy. It follows from the analysis in sections IV and VI that (i) wage compression under an optimal wage determination mechanism and (ii) wage spreading induced by an optimal industrial policy layered on top of decentralized bargaining provide alternative mechanisms for achieving an efficient number and mix of jobs.

Section VI also considers solutions to parametric versions of the model that are designed to assess the welfare implications of alternative wage-setting and industrial policy regimes. Reasonable parametrizations of the model suggest that an efficient wage or optimal tax structure can substantially alter the job distribution and thereby bring about a large increase in average labor productivity. However, sizable wage and productivity differentials among identical workers do not imply large welfare gains associated with a move 
to an efficient job distribution. As a related point, the size of welfare improvements that result from a movement to the efficient job distribution exhibits little connection to the size of productivity improvements. Higher unemployment and greater job creation costs generate this wedge between the productivity gains and welfare gains associated with the move to an efficient job distribution.

The contrast between outcomes under decentralized wage determination and outcomes under the efficient wage structure points toward an efficiency-enhancing role for a centralized wage-setting institution. Section VII considers an institution in which a labor union and an employer confederation bargain over the parameters of the wage structure prior to job creation and search. Numerical calculations indicate that centralized wage determination exhausts much, sometimes nearly all, of the potential efficiency gains associated with moving to first-best outcomes. Under reasonable constraints on wage-setting and enforcement powers, the centralized bargaining authority substantially compresses the wage structure relative to outcomes under decentralized bargaining. The analysis provides an efficiency rationale for centralized wage-setting institutions and an explanation for why they tend to compress the wage distribution.

Section VIII briefly discusses the relationship between the analysis in this paper and related work. Section IX offers some concluding remarks.

\section{The Quality Distribution of Jobs}

\section{A. A Bare-Bones Search Model with Costly Job Creation}

Real-world economies present a wide range of potential job creation opportunities. Potential jobs differ in the attractiveness of their attributes and in the costs of their creation. To model these aspects of the job creation process, assume that firms competitively sup- 
ply $I$ types of jobs according to the cost-of-creation schedules $C^{i}\left(J^{i}\right), i=1,2, \ldots I$, where $C^{i}\left(J^{i}\right)$ denotes the total cost of creating $J^{i}$ jobs of type $i$. The marginal cost schedules are positive and increasing for positive values of $J^{i}$.

These assumptions about the cost-of-creation schedules admit a range of interpretations regarding ex ante heterogeneity among firms. One interpretation posits ex ante identical firms and a job creation technology that requires a job-type specific input subject to a rising supply price. Another interpretation posits firms that have different job creation costs and some scarce factor at the firm level. Under this interpretation, the degree of heterogeneity amongs firms determines the convexity of the cost-of-creation schedules. This second interpretation also implies positive expected rents for infra-marginal job-creating firms.

The analysis below presumes that job types differ in terms of anticipated productivity, but the form of ex ante heterogeneity is inessential for the central results. It will be convenient to order job types by $y^{i}$, the ouput of a type- $i$ job when matched to a worker. Unfilled jobs produce nothing.

The economy also contains $L$ workers, each of whom produces $y^{i}$ when matched to a type- $i$ job in the market sector. Unmatched workers receive an imputed income $z$ in the nonmarket sector.

Workers and firms engage in a single round of search, during which they meet randomly in pair-wise fashion. The aggregate number of meetings obeys the CRS matching technology

$$
M(L, J)=a L^{1-\alpha} J^{\alpha}, \quad 0<\alpha<1
$$

where $J$ equals the total supply of jobs, and where the parameter $a$ is such that $a L^{1-\alpha} J^{\alpha}<$ $L, J$ in equilibrium. ${ }^{3}$ It follows from this technology and the random meeting assumption ${ }^{3}$ Equation (1) is the standard specification of the matching technology that underlies mod- 
that each worker finds a job with probability $P_{w}=a(J / L)^{\alpha}$, each firm fills a vacancy with probability $P_{f}=a(J / L)^{\alpha-1}$, and that $\left(J^{i} / J\right)$ equals the fraction of meetings involving type- $i$ jobs.

Upon meeting, workers and firms engage in a (nonsymmetric) Nash bargain to determine the division of the match surplus. In particular, wages solve

$$
\max ^{i} \quad\left(w^{i}-z\right)^{\beta}\left(y^{i}-w^{i}\right)^{1-\beta}, \quad \text { for } i=1,2, \ldots, I,
$$

where $\beta, 0<\beta<1$, is a parameter that determines the fraction of the match surplus obtained by the worker. ${ }^{4}$

This completes the specification of the model. Equilibrium entails an equality - for each job type - between the expected profit associated with a vacancy and the cost of creating the marginal vacancy.

\section{B. The Efficiency Condition with a Single Job Type}

Consider the efficiency properties of job creation behavior when there is a single job type. To compute equilibrium job creation, observe first that the value of a vacancy is given by

$$
V=P_{f}(y-w)+\left(1-P_{f}\right) 0=a(J / L)^{\alpha-1}(1-\beta)(y-z),
$$

using the definition of $P_{f}$ and the wage equation implied by the Nash bargaining problem,

$$
w=\beta y+(1-\beta) z=z+\beta(y-z)
$$

In equilibrium, the value of a vacancy equals the cost of creating the marginal job,

$$
P_{f}(1-\beta)(y-z)=a(J / L)^{\alpha-1}(1-\beta)(y-z)=C^{\prime}(J)
$$

ern interpretations of the Beveridge curve relationship between unemployment and vacancies. See Blanchard and Diamond (1989) and Pissarides (1990).

${ }^{4}$ This parametrization of the bargaining solution is common in search equilibrium models; see, e.g., Pissarides (1990). Kalai (1977) provides an axiomatic justification. 
which implies the equilibrium job supply function

$$
\bar{J}=J(\underset{(+)}{a}, \underset{(+)}{L}, \underset{(?)}{\alpha}, \underset{(-)}{\beta}, \underset{(+)}{y}, \underset{(-)}{z}) .
$$

To determine the efficiency properties of (4) and (5), consider a social planner who chooses job creation to solve

$$
\max _{J} a L^{1-\alpha} J^{\alpha} y+\left[L-a L^{1-\alpha} J^{\alpha}\right] z-C(J)
$$

The first-order condition to this problem states that the socially optimal supply of jobs satisfies

$$
P_{f} \alpha(y-z)=a(J / L)^{\alpha-1} \alpha(y-z)=C^{\prime}(J),
$$

Comparing (4) to the social optimality condition (7), we obtain the following efficiency characterization of equilibrium job creation:

$$
\begin{cases}\beta<1-\alpha \Rightarrow & \text { equilibrium job supply is too high; } \\ \beta=1-\alpha \Rightarrow & \text { equilibrium job supply is socially optimal } \\ \beta>1-\alpha \Rightarrow & \text { equilibrium job supply is too low. }\end{cases}
$$

Condition (8) reproduces the standard condition for efficient participation behavior in twosided search models with a CRS meeting technology. This condition extends directly to infinite-horizon models that encompass capital accumulation, endogenous search intensity, stochastic match quality, and a variable labor force (Hosios, 1990, and Pissarides, 1990, chapter 7).

To interpret the efficiency condition, observe that firms' job creation decisions involve negative and positive trading externalities: each additional job reduces the match probability for firms, $P_{f}$, while simultaneosly increasing the match probability for workers, $P_{w}$. The relative size of these externalities depends on $\alpha$, which can be interpreted as the elasticity of firm-worker meetings with respect to the number of jobs created. Thus, the 
creation of one additional job causes gross output to rise by the fraction $\alpha$ of the expected surplus associated with an additional job. It is socially optimal to create an additional job, if this increment to expected gross output exceeds the cost of creating the job. In equilbirum, firms create additional jobs to the point where their fraction, $(1-\beta)$, of expected match surplus equals the cost of an additional job. Thus, the wage determination process induces efficient job creation behavior by firms only when $(1-\beta)=\alpha$.

C. The Efficiency Conditions with a Multiplicity of Job Types

With multiple job types, equations (2)-(4) generalize directly, yielding

$$
\begin{gathered}
V^{i}=P_{f}\left(y^{i}-w^{i}\right)=a(J / L)^{\alpha-1}(1-\beta)\left(y^{i}-z\right), \\
w^{i}=\beta y^{i}+(1-\beta) z=z+\beta\left(y^{i}-z\right), \quad \text { and } \\
P_{f}(1-\beta)\left(y^{i}-z\right)=a(J / L)^{\alpha-1}(1-\beta)\left(y^{i}-z\right)=C^{i \prime}\left(J^{i}\right),
\end{gathered}
$$

for $i=1,2, \ldots, I$.

Equation $\left(4^{\prime}\right)$ governs the equilibrium quality distribution of jobs. To evaluate the efficiency properties of this quality distribution, consider the net social benefit of converting one type- $l$ job to a type- $h$ job, where $h>l$ :

$$
a(J / L)^{\alpha-1}\left(y^{h}-y^{l}\right)+C^{l \prime}\left(J^{l}\right)-C^{h \prime}\left(J^{h}\right) .
$$

To determine whether the equilibrium quality distribution is efficient, evaluate (9) at the decentralized outcome. From the equilibrium job supply conditions $\left(4^{\prime}\right)$,

$$
C^{l \prime}\left(J^{l}\right)-C^{h \prime}\left(J^{h}\right)=a(J / L)^{\alpha-1}\left(y^{l}-y^{h}\right)(1-\beta)=P_{f}\left(y^{l}-y^{h}\right)(1-\beta) .
$$

Substituting this condition into (9) yields

$$
a(J / L)^{\alpha-1}\left(y^{h}-y^{l}\right) \beta
$$


as the net social benefit of upgrading the quality distribution of jobs, evaluated at the decentralized equilibrium outcome. This expression is positive under any wage bargain that provides workers with at least part of the match surplus. Thus, we have proved that equilibrium job creation produces an excessive relative supply of inferior job types in the following sense: Holding the total number of jobs fixed, efficiency improves by shifting the mix of jobs towards higher productivity types.

The reason for an excessive relative supply of inferior jobs is clear. According to (10), firms obtain only a fraction $(1-\beta)$ of the extra expected surplus generated by upgrading the quality distribution, but they incur all of the additional costs. In consequence, the private incentives confronting job creators confer an inadequate premium on quality. Ironically, greater bargaining power on the part of workers worsens the quality distribution of available jobs.

We can now appreciate the fundamental tension between the condition for an efficient mix of jobs $(\beta=0)$ and the standard condition for an efficient total supply of jobs $(\beta=1-\alpha)$. If government policy and labor market institutions channel job surpluses to firms so as to produce an efficient job mix, firms will devote too many resources to job creation. Conversely, if government policy and labor market institutions support a bargaining environment that balances the positive and negative trading externalities implied by (1), firms will create an excessive relative supply of inferior jobs. Beginning from a situation where workers have substantial bargaining power $(\beta \geq 1-\alpha)$, a further increase in their bargaining power worsens efficiency along both dimensions.

To complete this discussion and lay the groundwork for later results, I draw on the preceding analysis to fully specify the socially optimal and decentralized equilibrium job supply behavior. The socially optimal supply of jobs is the solution to the $I$-equation 
system of efficient relative supply conditions,

$$
a\left(\sum_{k=1}^{I} J^{k} / L\right)^{\alpha-1}\left(y^{i+1}-y^{i}\right)+C^{i \prime}\left(J^{i}\right)-C^{i+1 \prime}\left(J^{i}\right)=0, \quad i=1,2, \ldots, I-1
$$

and the efficient total supply condition,

$$
a\left(\sum_{k=1}^{I} J^{k} / L\right)^{\alpha-1} \alpha \sum_{k=1}^{I} J^{k}\left(y^{k}-z\right)=\sum_{k=1}^{I} J^{k} C^{k \prime}\left(J^{k}\right)
$$

Using (4') and (10), the decentralized equilibrium supply of jobs is the solution to the parallel system:

$$
\begin{gathered}
(1-\beta) a\left(\sum_{k=1}^{I} J^{k} / L\right)^{\alpha-1}\left(y^{i+1}-y^{i}\right)+C^{i \prime}\left(J^{i}\right)-C^{i+1 \prime}\left(J^{i}\right)=0, \quad i=1,2, \ldots, I-1, \\
a\left(\sum_{k=1}^{I} J^{k} / L\right)^{\alpha-1}(1-\beta) \sum_{k=1}^{I} J^{k}\left(y^{k}-z\right)=\sum_{k=1}^{I} J^{k} C^{k \prime}\left(J^{k}\right) .
\end{gathered}
$$

Equations (12) and (13) will prove useful in the analysis below.

\section{The Quality Distribution in Alternative Environments}

\section{A. Search Technology and Search Intensity as a Function of Job Quality}

Because the opportunity cost of an unfilled job increases in job quality, firms with better jobs are motivated to search more intensively. In addition, firms offering better jobs may find it easier to attract workers at any given level of search expenditures. Introducing these factors into the model clearly shifts the equilibrium quality distribution toward better jobs. One might suspect, then, that plausible modifications to the search technology would overturn the efficiency characterization developed in section II. I now show that section II's central efficiency result continues to hold under a simple and natural formulation of the search intensity decision. 
To develop the argument, modify the bare-bones model as follows. Let $M(L, s J)=$ $a L^{1-\alpha}(s J)^{\alpha}, 0<\alpha<1$, be the number of meetings between firms and workers, where $s J$ equals the aggregate efficiency units of search effort supplied by firms. Let $s^{i}$ denote the efficiency units of search for a firm offering a type- $i$ job. For each efficiency unit supplied, there is a probability $M(L, s J) / s J$ of meeting a worker, so that the meeting probabilities become

$$
P_{f}^{i}=\left(s^{i} / s J\right) M(L, s J)=a s^{i}(s J / L)^{\alpha-1}, \quad i=1, \ldots, I, \quad \text { and } P_{w}=a(s J / L)^{\alpha} .
$$

Firms choose search intensity to maximize the net vacancy value

$$
V^{i}=a(s J / L)^{\alpha-1} s^{i}\left(y^{i}-w^{i}\right)-\sigma^{i}\left(s^{i}\right), \quad i=1, \ldots, I,
$$

where $\sigma^{i}(\cdot)$ is positive, increasing and strictly convex for each $i$ with $\sigma^{i}(0)=0$. To capture the idea that search is less costly for better job types, assume $\sigma^{h \prime}(x) \leq \sigma^{l \prime}(x)$ for $h>l$ and $x \geq 0$.

Under these assumptions, the search-intensity behavior of firms obeys the first-order condition,

$$
\sigma^{i \prime}\left(s^{i}\right)=a(s J / L)^{\alpha-1}\left(y^{i}-w^{i}\right)=a(s J / L)^{\alpha-1}(1-\beta)\left(y^{i}-z\right), \quad i=1, \ldots, I .
$$

According to this condition, optimal marginal search cost is higher for firms with better jobs. It follows that efficiency units of search per job rise with job quality for two reasons - greater incentive to search and lower search costs.

Endogenous search intensity leads to the slightly modified equilibrium job supply conditions,

$$
V^{i *}=a(s J / L)^{\alpha-1} s^{i *}(1-\beta)\left(y^{i}-z\right)=C^{i \prime}\left(J^{i}\right)+\sigma^{i *}, \quad i=1, \ldots, I,
$$

where an asterisk denotes a function evaluated at the privately optimal search intensity. 
We can now analyze the efficiency properties of the equilibrium quality distribution in the same manner as before. Holding search intensities and the supplies of other job types fixed at equilibrium levels, consider the net social benefit from converting one type- $l$ job to a type- $h$ job, $h>l$ :

$$
\begin{gathered}
a(s J / L)^{\alpha-1}\left[s^{h *}\left(y^{h}-z\right)-s^{l *}\left(y^{l}-z\right)\right]-\left[\sigma^{h *}+C^{h \prime}\left(J^{h}\right)\right]+\left[\sigma^{l *}+C^{l \prime}\left(J^{l}\right)\right] \\
+\left.\left(s^{h *}-s^{l *}\right) \sum_{i=1}^{I} J^{i}\left(y^{i}-z\right) \frac{\partial P_{f}^{i}}{\partial s}\right|_{s^{i}=s^{i *}}
\end{gathered}
$$

Evaluating at the equilibrium outcome, this expression becomes proportional to

$$
\left[s^{h *}\left(y^{h}-z\right)-s^{l *}\left(y^{l}-z\right)\right] \beta-\left[\left(s^{h *}-s^{l *}\right)(1-\alpha) J\right] \sum_{i=1}^{I}\left(\frac{s^{i *} J^{i}}{s J}\right)\left(y^{i}-z\right) \equiv \Phi(\beta),
$$

where $\Phi$ is a continuous function of $\beta$, satisfying $\Phi(0)<0$ and $\Phi(1-\alpha)>0$.

The first term of $\Phi$, analogous to (11), captures the direct efficiency gain from upgrading job quality. This efficiency gain now reflects the greater productivity and greater search intensity of the better job. The second term captures the efficiency loss implied by greater search for the upgraded job. The resulting increase in aggregate search intensity reduces the match probabilities for all firms. This efficiency loss equals the expected reduction in the number of matches times the average ex post surplus on filled jobs.

Using the properties of the $\Phi(\cdot)$ function, we can now see how endogenous search intensity modifies the efficiency characterization. First, with endogenous search intensity, channeling all match surplus to firms $(\beta=0)$ no longer produces an efficient mix of jobs. Instead, $\beta=0$ now leads to an excessive relative supply of better jobs. Conversely, $\beta=1-\alpha$ implies $\Phi>0$ and an excessive relative supply of inferior jobs. Second, applying the intermediate value theorem, there exists a $\beta \in(0,1-\alpha)$ that produces an efficient job mix. Hence, there remains a fundamental tension between the condition for 
an efficient number of jobs $(\beta=1-\alpha)$ and the modified condition for an efficient mix of jobs $(\beta<1-\alpha)$. I conclude from this analysis that the central efficiency result in section II does not stem from unduly restrictive assumptions regarding the search technology. ${ }^{5}$

\section{B. Ex Ante Sorting of Jobs into Separate Search Markets}

Neither endogenous search intensity nor easier search by better firms resolves the basic tension between relative and total supply efficiency condtions. These modifications to the search environment leave intact the crucial feature of the bare-bones model: the mixing of endogenously supplied heterogeneous jobs. To appreciate the crucial nature of the mixing feature, it is helpful to consider a model in which firms are perfectly sorted along the quality dimension into separate search markets. Location, for example, is an important job attribute that may be easily distinguished ex ante.

Suppose that workers are initially distributed among locations. Prior to searching for a job, workers can migrate between locations at a cost that may differ among workers and that may be contingent on destination and initial location. Job quality differs across locations, but - the critical assumption - it is identical for all firms at a particular location. After migration, job creation and search take place as in the bare-bones model.

Modifying the previous analysis to incorporate equilibrium conditions for intermarket

\footnotetext{
${ }^{5}$ The analysis in this section, and elsewhere in the paper, presumes that firms cannot effectively announce and commit to wage offers prior to meeting as an instrument for increasing arrival rates of workers. Barring an infinite elasticity of worker arrivals with respect to the promised wage (which would effectively restore an auction market), it does not appear that ex ante wage offers will generally produce an efficient job mix in search equilibrium. However, ex ante wage offers have a potentially important bearing on the size of the equilibrium departure from socially optimal outcomes.
} 
mobility, one obtains the following conditions for efficient equilibrium job supply:

$$
\beta^{i}=1-\alpha^{i},
$$

where $i$ indexes location and job quality. These conditions are simply the multi-market version of the standard condition (8), and they reduce to (8) when the available search technology is the same across locations. These conditions simultaneously achieve efficiency along relative and total supply margins under perfect ex ante sorting of jobs. The ex ante sorting eliminates the mixing of heterogeneous jobs that caused the tension between relative and total supply efficiency conditions in the previous models.

This brief discussion provides some insight into how other modifications to the search environment would affect the tension between total and relative supply efficiency conditions. Reputational mechanisms, for example, might facilitate the ex ante sorting of jobs in an environment with repeated transactions by the firm. Informational imperfections related, for example, to the experience-good nature of job quality would hamper ex ante sorting. In general, any mechanism that failed to achieve perfect ex ante sorting of jobs along all dimensions that workers care about would fail to eliminate the tension between relative and total supply efficiency conditions in the decentralized equilibrium. As a further point, since firms' incentives to advertise or disguise their quality depend on their relative position in the job quality distribution, there would seem to be considerable scope in richer models for a variety of equilibria with endogenously determined degrees of ex ante sorting.

\section{Endogenous Quality Distributions on Both Sides}

The efficiency analysis extends straightforwardly to endogenous quality determination

on both sides of the market. Consider, first, a symmetric specification that incorporates heterogeneity in worker quality and participation costs in a manner that mirrors the treat- 
ment of heterogeneity in job types and creation costs. Let $L^{n}$ denote the number of type- $n$ workers who choose to participate, and let $L$ denote the total number of worker participants. Let $f^{n i}$ denote the output produced by a match between a type- $n$ worker and a type- $i$ job.

In this environment, nonsymmetric Nash bargaining implies the wage equations

$$
w^{n i}=z+\beta\left(f^{n i}-z\right), \quad i=1, \ldots, I \text { and } n=1, \ldots, N
$$

Hence, wages reflect job-related and worker-related productivity differentials with equal force in the equilibrium with decentralized wage determination.

Evaluated at the equilibrium outcome under decentralized Nash bargaining, upgrading the job quality distribution enhances efficiency whenever

$$
\beta a(J / L)^{\alpha-1} \sum_{n=1}^{N}\left(L^{n} / L\right)\left(f^{n h}-f^{n l}\right)>0 \quad \text { for any } i=h, l
$$

and upgrading the worker quality distribution enhances efficiency whenever

$$
(1-\beta) a(J / L)^{\alpha} \sum_{i=1}^{I}\left(J^{i} / J\right)\left(f^{m i}-f^{p i}\right)>0 \quad \text { for any } n=m, p
$$

It follows that relative job supplies are efficient if, and only if, $\beta=0$; whereas relative worker supplies are efficient if, and only if, $\beta=1$.

The same tension between efficiency requirements arises when workers make human capital investment decisions prior to job matches. To see this point, assume that workers can achieve human capital level $h$ at a cost $K(h)$, where $K(\cdot)$ is increasing and convex. Let $f^{i}(h), f^{\prime}(\cdot)>0$, denote worker output on a type- $i$ job. Under these assumptions, privately optimal worker investment decisions satisfy

$$
K^{\prime}(h)=z+\beta a(J / L)^{\alpha} \sum_{i=1}^{I}\left(J^{i} / J\right)\left[f^{i}(h)-z\right]
$$


but socially efficient human capital investment requires

$$
K^{\prime}(h)=z+a(J / L)^{\alpha} \sum_{i=1}^{I}\left(J^{i} / J\right)\left[f^{i}(h)-z\right] .
$$

Clearly, too little human capital investment occurs unless $\beta=1$.

Thus, the basic message is the same in both the participation and human capital investment models. When wages are determined in a decentralized manner, there is a fundamental tension between the requirement for an efficient mix of workers and the requirement for an efficient mix of jobs. Both the efficient worker mix and the efficient job mix conditions differ from the standard condition for an efficient total supply of workers and jobs. Since both workers and firms are likely to extract part of the match surplus, both worker quality and job quality are too low in the decentralized equilibrium.

\section{The Efficient Wage Structure}

\section{A. Efficient Wages with an Endogenous Job Quality Distribution}

Thus far, the efficiency analysis of the job quality distribution assumes that wage determination occurs in a decentralized manner as the outcome of independent Nash bargains. A natural and important line of inquiry considers how the efficiency characteristics of the job quality distribution are affected by alternative bargaining solutions and by labor market institutions that facilitate centralized wage determination. Here, I address an important question related to this line of inquiry: What are the properties of a wage structure that induces an efficient number and mix of jobs? I consider the consequences of centralized wage bargaining between firms and workers in section VII.

We can represent an arbitrary wage determination mechanism by a set of parameters

$\left\{\beta^{i}\right\}_{i=1}^{I}$ that govern the sharing of match surplus for each job type. Positive levels of participation by workers and jobs require $0 \leq \beta^{i} \leq 1$ for all $i$. In terms of these sharing 
parameters, private job supply decisions in the bare-bones model satisfy

$$
P_{f}\left(1-\beta^{i}\right)\left(y^{i}-z\right)=a(J / L)^{\alpha-1}\left(1-\beta^{i}\right)\left(y^{i}-z\right)=C^{i \prime}\left(J^{i}\right), \quad i=1,2, \ldots, I .
$$

As before, (9) expresses the net social benefit from converting one type-l job to a type- $h$ job, $h>l$. Combining $\left(4^{\prime \prime}\right)$ and (9) yields a restriction on any pair $\left\{\beta^{h}, \beta^{l}\right\}$ that induces an efficient relative supply of the two job types; namely, $\beta^{h} / \beta^{l}=\left(y^{h}-z\right) /\left(y^{l}-z\right)$. More generally, the complete set of sharing parameters brings about an efficient mix of jobs if, and only if,

$$
\beta^{i+1} / \beta^{i}=\left(y^{i}-z\right) /\left(y^{i+1}-z\right), \quad i=1,2, \ldots, I-1 .
$$

An efficient number of jobs requires equivalence between the total supply condition (12.b) and a suitably generalized version of (13.b),

$$
a\left(\sum_{k=1}^{I} J^{k} / L\right)^{\alpha-1} \sum_{k=1}^{I}\left(1-\beta^{k}\right) J^{k}\left(y^{k}-z\right)=\sum_{k=1}^{I} J^{k} C^{k \prime}\left(J^{k}\right) .
$$

Thus, a set of sharing parameters brings about an efficient total supply of jobs if, and only if,

$$
\alpha \sum_{k=1}^{I} J^{k}\left(y^{k}-z\right)=\sum_{k=1}^{I}\left(1-\beta^{k}\right) J^{k}\left(y^{k}-z\right)
$$

The unique set of surplus sharing parameters that solve (16) and (17) is given by

$$
\beta^{i}=(1-\alpha) \frac{\sum_{k=1}^{I}\left(J^{k} / J\right)\left(y^{k}-z\right)}{\left(y^{i}-z\right)} \quad i=1, \ldots, I .
$$

This equation generalizes the standard efficiency condition (8) in Diamond-MortensenPissarides models to encompass multiple, endogenously supplied job types. (See Hosios (1990) and Pissarides (1990).) The new term in this condition multiplies $(1-\alpha)$ by the ratio of the weighted-average match surplus to match surplus for a type- $i$ job. Hence, 
under an efficient wage structure, better jobs grant a smaller share of match surplus to workers than inferior jobs. There is no apparent reason for a wage structure with this characteristic to emerge in a fully decentralized setting.

It is useful to translate (18), which is a statement about the structure of efficient sharing parameters, into a direct statement about the wage structure. Since $w^{i}=z+$ $\beta^{i}\left(y^{i}-z\right)$, the efficient wage structure implied by (18) is

$$
w^{i}=z+(1-\alpha) \sum_{k=1}^{I}\left(J^{k} / J\right)\left(y^{k}-z\right), \quad i=1, \ldots, I .
$$

Hence, under the efficient wage structure, all job types offer a wage equal to the opportunity cost of workers' time, plus the fraction $(1-\alpha)$ of the average match surplus. Here, the "wage" is appropriately interpreted as encompassing nonpecuniary aspects of worker compensation; in other words, the efficient wage structure entails full equalization of jobrelated utility differences.

At first sight, the result that an optimal wage structure completely compresses productivity differentials might appear to violate the classical efficiency dictum that wages fully reflect productivity differentials. But the classical dictum pertains to productivity differentials associated with worker traits, whereas (19) pertains to productivity differentials associated with job characteristics. Complete wage compression generates an efficient job mix in this model, because it enables firms to capture all rents that derive from upgrading job quality. As we saw in section II.C, the inability of firms to capture these rents under decentralized bargaining induces an excessive relative supply of inferior jobs. Wage compression resolves this problem.

The favorable consequences of wage compression in this search model contrast sharply with their adverse consequences in efficiency wage models based on effort elicitation prob- 
lems. ${ }^{6}$ Bulow and Summers (1986), for example, develop a model with imperfect monitoring of worker effort in primary sector jobs and costless monitoring in secondary sector jobs. If it is infeasible for workers to post performance bonds or otherwise "buy" jobs, the resulting equilibrium entails a wage premium for primary sector jobs and, consequently, an inefficiently low level of primary sector employment. In this type of efficiency wage model wage compression causes secondary sector employment to expand at the expense of primary sector employment (Bulow and Summers, 1986, page 392), which further worsens the already inefficient composition of economic activity.

Table 1 illustrates how various factors influence the efficient sharing parameters, the wage, and the resulting distribution of job types. The table entries are computed from $\left(4^{\prime \prime}\right),(18)$ and (19) assuming that $C^{i}\left(J^{i}\right)=g^{i}\left(J^{i}\right)^{\gamma}, g^{i}, \gamma>0$ for $\mathrm{i}=1,2$. This specification implies positive job creation for both types in the equilibrium with decentralized wage determination.

Row (7) of the table shows that lower quality jobs are sometimes squeezed out entirely by an efficient wage structure. It can be efficient to eliminate lower quality jobs, even when these jobs entail large amounts of surplus ex post. The remaining rows indicate how the job supply elasticity parameter $(\gamma)$, the elasticity of matches with respect to job creation $(\alpha)$, and the opportunity cost of worker time affect the efficient distribution of job types and the range of the efficient sharing parameters among active job types.

To sum up, the efficient wage structure entails full compression of job-related productivity differentials - that is, equal wages among identical workers. Efficient wage compression involves a smaller fraction of match surplus accruing to workers on better jobs. Relative to the equilibrium outcome under decentralized bargaining, the efficient wage structure induces larger relative supplies of better jobs and, possibly, a truncation

\footnotetext{
${ }^{6}$ Stiglitz (1987) and Weiss (1990) review the theoretical literature on efficiency wages.
} 
from below of the job quality distribution. In the light of these results, section VII below considers the potential efficiency-enhancing role of centralized wage-setting institutions.

\section{B. Efficient Wages with Two-Sided Endogenous Quality Distributions}

Although the algebra is tedious, one can generalize the preceding analysis of the efficient wage structure to accommodate two-sided endogenous quality distributions. For the symmetric, two-sided quality model in section III.C, the efficient wage structure exhibits the following properties:

$$
\begin{gathered}
\sum_{n=1}^{N}\left(L^{n} / L\right) w^{i+1, n}=\sum_{n=1}^{N}\left(L^{n} / L\right) w^{i n}, \quad i=1, \ldots, I-1, \text { and } \\
\sum_{i=1}^{I}\left(J^{i} / J\right)\left(f^{i, n+1}-f^{i n}\right)=\sum_{i=1}^{I}\left(J^{i} / J\right)\left(w^{i, n+1}-w^{i n}\right), \quad n=1, \ldots, N-1 .
\end{gathered}
$$

According to (20), the efficient wage structure equalizes expected wages across jobs with different productivities, where the expectation is calculated over the distribution of worker types. This condition is a simple and natural generalization of condition (19). According to (21), the efficient wage structure fully reflects expected productivity differences that stem from worker traits. Putting the pieces together delivers the following theorem: relative to the efficient wage structure, the wage structure under decentralized bargaining entails too much compression of worker-related productivity differentials and too little compression of job-related productivity differentials.

\section{Analytical Solutions for Parametric Versions of the Model}

With suitable assumptions about the form of the job creation cost functions, one can obtain explicit analytical solutions for the quality distribution of jobs and the structure of wages in the decentralized equilibrium of the basic model. One can also solve for the efficient wage characterized in section IV and the resulting quality distribution. 
Figure 1 displays the decentralized equilibrium and efficient quality distributions of jobs under the assumption that the creation cost schedules satisfy

$$
C^{i}=g^{i}\left(J^{i}\right)^{\gamma}, \quad i=1, \ldots, 100
$$

In constructing the figure, I have chosen the $g^{i}$ parameters to produce a uniform distribution of job types in the decentralized equilibrium. ( $g_{1}$ is set to one - a normalization.) The search efficiency parameter (a) is set to achieve a $5 \%$ unemployment rate in the decentralized equilibrium with Nash wage bargaining $(\beta=.5)$. The least productive job is set to $110 \%$ of the workers' reservation value, and the most productive job is set to deliver a value of roughly .43 for the standard deviation of log wages in the decentralized Nash

outcome. This value corresponds to the standard error of the residual in a regression of log hourly wages on an extensive set of experience, education and sex controls for the U.S. manufacturing sector in 1987. See Figure 1 in Davis and Haltiwanger (1991).

Table 2 displays other outcomes that correspond to the job distributions displayed in Figure 1. Table 3 shows that the welfare gains afforded by an efficient wage structure are much smaller than the gains in average labor productivity. For example, consider the decentralized equilibrium with $\beta=\alpha=.5$, so that the total supply efficiency condition holds. Relative to this decentralized equilibrium, an efficient wage structure raises average labor productivity by more than five percent (from 126.8 to 133.4), but it raises net per capita income by less than one-half percent (from 119.12 to 119.66). The main reason for this large gap between productivity and welfare gains is the much higher level of unemployment under the efficient wage structure.

\section{Tax Policy with Decentralized Wage Determination}

\section{A. The Structure of the Optimal Policy}

As in many other models that generate wage differentials among identical workers, 
the search models in this paper imply an efficiency-enhancing role for employment tax and subsidy policies that alter the composition of economic activity. In the bare-bones model, the optimal tax structure achieves the same number and mix of jobs as the efficient wage structure, but it magnifies rather than eliminates pre-existing wage differentials. In contrast to models where effort elicitation problems underlie wage differentials among identical workers (e.g., Bulow and Summers, 1986), optimal policy in the search model need not entail an absolute subsidy to high wage/high productivity jobs. Nor is the size of the welfare improvement induced by an optimal policy closely related to the magnitude of pre-existing wage differentials.

To derive the optimal tax structure in the basic model, first reformulate equations $\left(3^{\prime}\right)$ and $\left(4^{\prime}\right)$ to incorporate type-contingent employment taxes (subsidies, if negative):

$$
\begin{gathered}
w^{i}=\beta\left(y^{i}-T^{i}\right)+(1-\beta) z=z+\beta\left(y^{i}-z-T^{i}\right), \quad \text { and } \\
P_{f}(1-\beta)\left(y^{i}-z-T^{i}\right)=a(J / L)^{\alpha-1}(1-\beta)\left(y^{i}-z-T^{i}\right)=C^{i \prime}\left(J^{i}\right),
\end{gathered}
$$

for $i=1,2, \ldots, I$.

As before, expression (9) describes the net social benefit of ugrading the job quality distribution. Evaluating (9) at (23), and setting the resulting expression to zero, implies that the optimal tax structure satisfies

$$
T^{i}=T^{i+1}+[\beta /(1-\beta)]\left(y^{i+1}-y^{i}\right), \quad i=1, \ldots, I-1 .
$$

According to (24), the optimal tax structure favors more productive jobs, and the size of the differential subsidy increases in the workers' share of match surplus and in the size of the productivity differential.

It follows from (22) and (24) that wage differentials equal

$$
w^{i+1}-w^{i}=\frac{\beta}{1-\beta}\left(y^{i+1}-y^{i}\right)
$$


under the optimal tax structure, but they equal

$$
w^{i+1}-w^{i}=\beta\left(y^{i+1}-y^{i}\right)
$$

in the decentralized equilibrium with no taxes and subsidies. Thus, the optimal tax structure causes job-related productivity components of wage differentials to increase by a factor of $(1-\beta)^{-1}$ relative to the no-tax equilibrium.

The level of optimal taxes is pinned down by the efficient total supply requirement,

$$
\alpha \sum_{k=1}^{I} J^{k}\left(y^{k}-z\right)=(1-\beta) \sum_{k=1}^{I} J^{k}\left(y^{k}-T^{k}-z\right) .
$$

This restriction, in combination with (24), implies

$$
T^{I}=(1-\beta)^{-1}\left[(1-\beta-\alpha) \sum_{k=1}^{I}\left(J^{k} / J\right)\left(y^{k}-z\right)-\beta \sum_{k=1}^{I-1}\left(J^{k} / J\right)\left(y^{I}-y^{k}\right)\right] .
$$

Recall that the efficient job distribution is the solution to (12.a) and (12.b). Equations (24) and (27) determine the tax structure that sustains this efficient distribution in the equilibrium with decentralized wage determination.

\section{B. Numerical Experiments under Alternative Tax Policy and Wage-Setting Regimes}

Table 3 displays equilibrium outcomes under the optimal tax structure when wages are determined according to decentralized bargains. For comparison, the table also displays outcomes under two alternative regimes - decentralized wage bargains with no taxes and the efficient wage structure with no taxes. As in Table 1, the job creation cost schedules are $C^{i}\left(J^{i}\right)=g^{i}\left(J^{i}\right)^{\gamma}$ for $\mathrm{i}=1,2$. The welfare measure in Table 3 is per capita income net of job creation costs.

Several aspects of the table merit discussion. First, in line with equations (25) and (26), the optimal tax structure causes wage differentials to expand, often by large amounts. 
As the table verifies, the efficient wage structure achieves the same job distribution and per capita income level as the optimal tax structure, but it eliminates pre-existing wage differentials among identical workers. Thus, if earnings equality is viewed as desirable, wage compression dominates the optimal tax policy as a tool for achieving socially desirable outcomes.

Second, an efficient wage or optimal tax structure can substantially alter the job distribution and thereby bring about a large increase in average labor productivity. For example, in row (2) of the table an efficient wage or optimal tax structure reduces lowproductivity jobs' share of the total from $37 \%$ to $21 \%$, resulting in a $3.7 \%$ increase in productivity.

Third, sizable wage and productivity differentials among identical workers do not imply large welfare gains associated with a move to the efficient job distribution, as illustrated by row (7). As a related point, the size of welfare improvements that result from a move to the efficient job distribution exhibits little connection to the size of productivity improvements. Compare, for example, rows (3) and (4).

Fourth, gains in per capita income typically fall well short of gains in average labor productivity as a result of moving to an efficient wage or optimal tax structure. The relatively small improvement in per capita income can be understood as follows. Equation $\left(4^{\prime}\right)$ implies that better jobs cost more to create in the inefficient, no-tax equilibrium. The relative cost of creating better jobs rises further as the economy moves toward the efficient mix of jobs. Thus, the gains from higher average productivity at the efficient job mix are partly offset by the higher average cost of job creation. In addition, when $\alpha=1-\beta$, unemployment is always higher at the efficient outcome. ${ }^{7}$ Holding fixed the number of

\footnotetext{
${ }^{7}$ More generally, unemployment is typically higher at the efficient outcome unless $\alpha$ is substantially less than $1-\beta$.
} 
jobs, an increase in average job productivity raises the expected cost of the congestion externality associated with creating one more job of either type. Thus, upgrading the quality distribution of jobs implies a decline in the efficient number of jobs and a rise in unemployment. On net, the increase in average job creation costs and the rise in unemployment offset much of the gain in average labor productivity.

Fifth, the scope for welfare improvements engineered by an efficient wage or optimal tax structure is greater when the total supply efficiency condition $(\alpha=1-\beta)$ fails to hold. To see this point, compare rows (1), (3), (5) and (6) in Table 2 with rows (2), (4) and (7). In the first set of rows $\alpha \neq 1-\beta$, and welfare gains range from $1.5-3.5 \%$ of initial per capita income; in the second set of rows $\alpha=1-\beta$, and welfare gains range from $.1 \%$ to $.7 \%$ of initial per capita income.

Finally, and unlike efficiency wage models based on effort elicitation problems, the optimal subsidy for high wage jobs is not closely related to the size of the wage differential. Indeed, the optimal policy sometimes calls for a tax on employment in both job types. This outcome can arise when weak bargaining power by workers $(\beta<1-\alpha)$ results in too much job creation and overly congested search by firms. While this particular outcome might seem implausible, the general point is that the size of the optimal employment subsidy depends crucially on the search technology and relative bargaining power, as well as on the size of the productivity differentials between job types.

\section{Wages and Job Quality with Centralized Wage Determination}

In the context of the basic model, consider a labor union and an employer confederation that bargain over the wage structure prior to job creation and search. All workers belong to the union, and all firms belong to the employer confederation. Assume that the labor union and employer confederation act as perfect agents for their respective member- 
ships.

Since workers are risk-neutral and identical, it follows that the labor union wants to maximize wages plus the imputed value of leisure. In contrast, the employer confederation consists of firms that may differ in terms of both job creation costs and job quality. ${ }^{8}$ This heterogeneity implies potential conflict among firms regarding preference orderings over alternative wage structures. I assume that the employer confederation fully circumvents these conflicts and seeks to maximize aggregate net profits. In principle, side payments within the employer confederation can be used to insure that all firms share in the profit gains from centralized bargaining.

Given these preferences, the labor union and employer confederation engage in a (possibly nonsymmetric) Nash bargain over the wage structure, with threat points defined by outcomes under decentralized bargaining. Denote the threat point outcomes for workers and firms by $\bar{W}(\beta)$ and $\bar{F}(\beta)$, respectively, where $\beta$ equals the worker's share of match surplus in the decentralized Nash bargaining outcome. Let $\beta^{c}$ denote workers' share of the (additional) surplus that results from centralized bargaining.

Formally, the centralized wage bargaining problem is

$$
\max _{\left\{w^{i}\right\}_{i=1}^{I}}\left[W\left(w^{1}, \ldots, w^{I}\right)-\bar{W}(\beta)\right]^{\beta^{c}}\left[F\left(w^{1}, \ldots, w^{I}\right)-\bar{F}(\beta)\right]^{1-\beta^{c}}
$$

subject to the competitive job creation schedules,

$$
a(J / L)^{\alpha-1}\left(y^{i}-w^{i}\right)=C^{i \prime}\left(J^{i}\right), \quad i=1, \ldots, I,
$$

where

$$
W\left(w^{1}, \ldots, w^{I}\right)=L a(J / L)^{\alpha} \sum_{i=1}^{I}\left(J^{i} / J\right) w^{i}+L z\left[1-a(J / L)^{\alpha}\right], \quad \text { and }
$$

\footnotetext{
${ }^{8}$ Recall from section II.A that firm heterogeneity is one interpretation of convexity in the cost-of-creation schedule for jobs.
} 


$$
F\left(w^{1}, \ldots, w^{I}\right)=a(J / L)^{\alpha-1} \sum_{i=1}^{I} J^{i}\left(y^{i}-w^{i}\right)-\sum_{i=1}^{I} C^{i}\left(J^{i}\right)
$$

for $i=1, \ldots, I$.

I have been unable to make much progress in deriving general characterizations of the solution to (28)-(29), so I turn immediately to the results of a numerical analysis. Table 4 shows wage structure, per capita income, job distribution, and average productivity outcomes for a particular parametrization of the model under three alternative wage determination regimes. The top row of the second panel reports outcomes under the efficient wage structure. Remaining rows report outcomes under decentralized or centralized Nash wage bargaining for different values of $\beta$ and $\beta^{c}$. Recall that $\beta$, workers' share of match surplus in the decentralized wage bargain, determines the threat points in the centralized Nash bargain and thereby influences the wage structure outcome.

Three results stand out in Table 4. First, centralized bargaining increases average labor productivity to the level that prevails under the first-best outcomes with an efficient wage structure. Second, centralized bargaining exhausts a large fraction of the potential gains in net per capita income associated with a move to first-best outcomes. Indeed, when bargaining power is equally distributed in the underlying decentralized bargaining regime $(\beta=.5)$, centralized bargaining reaps essentially all potential efficiency gains. Third, centralized bargaining has dramatic effects on the wage structure. Wages differentials diminish sharply as a result of centralized bargaining when $\beta$ equals or exceeds .5. For small values of $\beta$, centralized bargaining produces large wage differentials opposite in sign to the differentials that prevail under decentralized bargaining.

To understand this last result, note that the centralized wage structure effectively punishes firms that create low-quality jobs by granting a relatively small portion of match surplus on these jobs. This pattern arises for all values of $\beta$ and $\beta^{c}$. Evidently, when firms 
garner most of the rents in the decentralized bargaining regime (i.e., when $\beta$ is small), this punishment aspect of the centralized wage structure manifests itself in especially stark fashion.

The wage structure results in Table 4 bear out one problematic aspect of the centralized bargaining problem as formulated in (28) and (29). For example, to implement the wage structure outcomes illustrated in Table 4 for $\beta=.2$, the bargaining authority must first identify low-productivity jobs and then force these jobs to pay higher wages. In practice, limitations on available information, verification ability, and enforcement powers are likely to render these wage structure solutions infeasible. Motivated by these considerations, it would be useful to formulate centralized wage bargaining problems that entail weaker informational and enforcement requirements.

\section{Related Work}

This paper was originally presented at a conference in honor of Assar Lindbeck that took place in Stockholm in June 1995. Earlier drafts of the paper were circulated in 1992 and 1993. The current draft is essentially identical to the 1995 version, except for this section and an improved ordering of the material in earlier sections. At this juncture (August 2001), some brief remarks on how this paper fits with concurrent and later research are in order.

Between the first draft and the 1995 draft, I became aware of three other papers that also model search environments with endogenously supplied heterogeneous types. Published versions of these papers appeared as Acemoglu (1996), Bertola and Caballero (1994) and Sattinger (1995). Portions of the analysis in Acemoglu (1996) overlap closely

with this paper. In particular, he independently proved that a search equilibrium with decentralized bargaining leads to under investment in job and worker quality. See his 
Proposition 2. More generally, the mixing of heterogeneous types that are endogenously supplied to search environments is an important theme in Acemoglu (1996) and several of his other papers.

Ljungqvist and Sargent (2000, pages 582-589) study an infinite-horizon version of the bare-bones model in Section II. They show that several of my results carry over to the steady state in an infinite-horizon setting. In particular, (a) the search equilibrium with decentralized wage setting exhibits an excessive relative supply of inferior jobs (unless firms capture the entire match surplus), (b) there is a fundamental tension between the relative and total job supply efficiency conditions of the same form as derived above, and (c) perfect ex ante sorting of different job types into separate search markets eliminates the excess relative supply of inferior jobs and resolves the tension between total and relative supply efficiency conditions. Following Moen (1987), they also show that under certain conditions competitive wage announcements by firms prior to search can effectively separate the markets in the optimal way and achieve an efficient total and relative supply of jobs.

Another related line of work, associated most closely with an important series of papers by Caballero and Hammour (1998, e.g.), explores the macroeconomic implications of relationship-specific investments by capital and labor. These investments - which may but need not derive from costly match formation - give rise to hold-up problems, or "appropriability" problems in the language of Caballero and Hammour. As they show, unresolved appropriability problems can lead to a number of bad macroeconomic outcomes including under investment by appropriated factors, undesirably slow adoption of new technologies, delayed job creation and excessive unemployment in response to bad shocks, and bottleneck problems in response to good shocks. They also emphasize that the failure to resolve appropriability problems at the micro level often gives rise to policy and institutional responses at the macro level. 
It is useful to relate selected results in this paper to the perspective and analysis of Caballero and Hammour. First, the excessive relative supply of inferior types in search equilibrium with decentralized wage setting can be seen as one manifestation of the generic tendency to under investment in environments with unresolved hold-up problems. Second, the fundamental tension between relative and total supply efficiency conditions shows that it can be impossible to achieve efficient factor supplies with decentralized wage setting. While ex ante sorting mechanisms relax this tension, they are unlikely to operate perfectly in real-world settings. Third, industrial policy (Section VI) and centralized wage determination (Section VII) are two possible institutional responses to the appropriability problems created by costly match formation. My analysis shows that these institutions can improve upon fully decentralized outcomes, but it should be emphasized that they bring their own problems that are largely ignored in this paper. ${ }^{9}$ Fourth, the efficient wage structure analysis in Section IV suggests that the requirements for fully efficient factor supply patterns are highly demanding and hard to achieve for any institution.

My analysis also points to a potentially important limitation of the models emphasized by Caballero and Hammour. In their models, labor typically appropriates a portion of the quasi-rents generated by capital, or vice versa. While each factor is susceptible to appropriation, only one factor suffers appropriation in equilibrium. In contrast, my analysis shows that search environments with two-sided endogenous heterogeneity exhibit simultaneous appropriation of each factor by the other, but along different investment margins. In other words, countervailing powers to appropriate by capital and labor do not fully net out when match formation is costly and both sides undertake specific investments. As a consequence, there is under investment on both sides of the market.

\footnotetext{
${ }^{9}$ For empirical evidence that centralized wage bargaining compresses the wage structure and thereby alters the distribution of jobs, see Davis and Henrekson (2001).
} 
In this regard, the Caballero and Hammour paradigm seems quite apt for traditional industrial settings in which capital or labor is fairly homogeneous. However, modern production and employment relationships often involve highly specific investments by firms and workers along several distinct dimensions, as well as costly match formation and breakup. Hence, institutional and policy responses that achieve a rough "balance" between the appropriation powers of capital and labor may work reasonably well in traditional industrial setting but quite poorly in other settings that seem increasingly important in modern economies.

There are also other differences between the consequences of appropriation problems emphasized by Caballero and Hammour and results in this paper. For example, the appropriating factor is typically under employed or partially excluded from the joint production sector in the models of Caballero and Hammour. In contrast, under employment of the appropriating factor is not a general feature of the search models considered here. Table 2 illustrates this point for the basic model with heterogeneous jobs and homogeneous workers. Under decentralized wage setting, labor appropriates quasi-rents from firms, which leads to under investment in job quality but higher - not lower - employment for the appropriating factor.

\section{Concluding Remarks}

The basic logic developed in this paper can be summarized in a few sentences. In search equilibrium with decentralized wage determination, firms recover only a fraction of the increases in ex post surplus that they generate by improving job quality ex ante, but they incur all of the costs. Hence, firms under invest in job quality from a social efficiency standpoint. Likewise, workers' inability to fully capture increases in match surplus generated by their ex ante investments lead them to under invest in human capital. The 
resulting search equilibrium exhibits excessive relative supplies of inferior jobs and inferior workers.

Absent some policy intervention or institutional response, it is generally impossible to achieve efficient supplies of heterogeneous workers and jobs in a search environment with decentralized wage bargaining. The restriction on wage bargaining required for an efficient total supply of workers and jobs conflicts with the restriction required for an efficient relative supply of different job types, and both conflict with the restriction required for an efficient relative supply of different worker types. Interventions in the form of an optimal tax and subsidy policy or a centralized wage-barganing authority can, in principle, substantially improve matters and drive the economy to more efficient or even first-best outcomes.

The details of a particular search model are likely to represent a very crude approximation to the costly transaction process that takes place in actual labor markets. But the key feature of the search models in this paper seems important in real-world labor markets; namely, that firms and workers incur substantial sunk costs that affect job and worker quality prior to meeting (or prior to negotiating worker compensation). This paper works out some key implications for the quality distributions of jobs and workers, the wage structure, and the potential efficiency-enhancing role of centralized wage-setting institutions that follow from the existence of these sunk costs in search equilibrium.

While the models in this paper facilitate the transparent development of these implications, they are too simplistic to provide a solid basis for assessing their quantitative importance. In some work in progress, I explore the effects of alternative bargaining environments and government policy choices in dynamic search models with endogenous job quality distributions. The analyis focuses on expected job duration, rather than productivity, as the aspect of quality that differentiates jobs. This focus is motivated by the 
apparently strong desire for stable jobs by workers in many sectors of the economy, and by the observation that job loss often entails large pecuniary and nonpecuniary losses. In this type of dynamic search environment, there is a natural policy role whereby job creation subsidies and job destruction taxes can be used to improve the mix and number of jobs. 


\section{References}

Acemoglu, Daron, 1996, "A Microfoundation for Social Increasing Returns in Human Capital Accumulation," Quarterly Journal of Economics, 111 (August), 779-804.

Becker, Gary, 1975, Human Capital, New York: Colombia University Press.

Bertola, Giuseppe and Ricardo J. Caballero, 1994, "Cross Sectional Efficiency and Labor Hoarding in a Matching Model of Unemployment," Review of Economic Studies, 61, no. 3 (July), 435-456.

Blanchard, Olivier and Peter Diamond, 1989, "The Beveridge Curve," Brookings Papers on Economic Activity, 1989:1, 1-60.

Bulow, Jeremy I. and Lawrence H. Summers, 1986, "A Theory of Dual Labor Markets with Application to Industrial Policy, Discrimination, and Keynesian Unemloyment," Journal of Labor Economics, 4, no. 3, part 1 (July), 376-414.

Caballero, Ricardo J. Mohamad L. Hammour, 1998, "The Macroeconomics of Specificity," Journal of Political Economy, 106, no. 4, 724-767.

Davis, Steven J. and John Haltiwanger, 1991, "Wage Dispersion Between and Within U.S. Manufacturing Plants, 1963-1986," Brookings Papers on Economic Activity, Microeconomics, $115-200$.

Davis, Steven J. and Magnus Henrekson, 2001, "Wage-Setting Institutions as Industrial Policy," NBER Working Paper No. 7502. Revised version available at http://gsbwww.uchicago.edu/fac/steven.davis/research.

Diamond, Peter A., 1981, "Mobility Costs, Frictional Unemployment, and Efficiency," Journal of Political Economy, 89, (August) 798-812.

Diamond, Peter A., 1982, "Wage Determination and Efficiency in Search Equilibrium," Review of Economic Studies, 49, (April) 217-227. 
Grout, Paul A., 1984, "Investment and Wages in the Absence of Binding Contracts," Econometrica, 52 (March), 449-460.

Hall, Robert and Edward Lazear, 1984, "The Excess Sensitivity of Layoffs and Quits to Demand," Journal of Labor Economics, 2 (April), 233-257.

Hosios, Arthur J., 1990, "On the Efficiency of Matching and Related Models of Search and Unemployment," Review of Economic Studies, 57, 279-298.

Kalai, E. (1977) "Nonsymmetric Nash Solutions and Replications of 2-Person Bargaining," International Journal of Game Theory, 6, 129-133.

Ljungqvist, Lars and Thomas J. Sargent, 2000, Recursive Macroeconomic Theory. Cambridge, MA: The MIT Press.

Moen, Espen, R., 1997, "Competitive Search Equilibrium," Journal of Political Economy, 105, no. 2, 385-411.

Mortensen, Dale T., 1982(a), "The Matching Process as a Non-Cooperative Bargaining Game," in J.J. McCall, ed., The Economics of Information and Uncertainty, Chicago: University of Chicago Press for the National Bureau of Economic Research.

Mortensen, Dale T., 1982(b), "Property Rights and Efficiency in Mating, Racing, and Related Games," American Economic Review, 72, (December) 968-979.

Parsons, Donald O., 1986, "The Employment Relationship: Job Attachment, Work Effort, and the Nature of Contracts," in Orley C. Ashenfelter and Richard Layard, eds., Handbook of Labor Economics, II, Amsterdam: North-Holland Press.

Pissarides, Christopher A., 1984, "Search Intensity, Job Advertising, and Efficiency," Journal of Labor Economics, 2, (January) 128-143.

Pissarides, Christopher A., 1990, Equilibrium Unemployment Theory, Basil Blackwell, Inc.: Cambridge, Massachusetts.

Sattinger, Michael, 1995, "Search and the Efficient Assignment of Workers to Jobs," 
International Economic Review, 36, no. 2 (May), 283-302.

Stiglitz, Joseph E., 1987, "The Causes and Consequences of the Dependence of Quality on Price," Journal of Economic Literature, 25 (March), 1-48.

Weiss, Andrew, 1990, Efficiency Wages: Models of Unemployment, Layoffs, and Wage Dispersion, Princeton, NJ: Princeton University Press 
Table 1. Efficient Sharing Parameters, Wage, and Job Distribution Under Alternative Parametrizations with Two Job Types

$\begin{array}{lllllllllll} & \alpha & \gamma & g^{2} / g^{1} & z & y^{1} & y^{2} & \beta^{1} & \beta^{2} & J^{1} / J & \text { Wage } \\ (1) & .5 & 2.0 & 1.0 & 50 & 90 & 100 & .58 & .46 & .39 & 73.07 \\ (2) & .5 & 2.0 & 2.0 & 50 & 90 & 100 & .55 & .44 & .56 & 72.19 \\ (3) & .5 & 1.2 & 2.0 & 50 & 90 & 100 & .53 & .42 & .79 & 71.03 \\ (4) & .5 & 1.2 & 1.0 & 50 & 90 & 100 & .62 & .49 & .08 & 74.62 \\ (5) & .5 & 2.0 & 1.0 & 60 & 90 & 100 & .61 & .46 & .35 & 78.25 \\ (6) & .5 & 2.0 & 1.0 & 50 & 80 & 100 & .76 & .46 & .21 & 72.93 \\ (7) & .5 & 2.0 & 1.0 & 50 & 75 & 100 & 1.00 & .50 & .00 & 75.00 \\ (8) & .3 & 2.0 & 1.0 & 50 & 90 & 100 & .82 & .66 & .29 & 82.95 \\ (9) & .7 & 2.0 & 1.0 & 50 & 70 & 100 & .68 & .27 & .15 & 63.66\end{array}$

Note:

Table entries are computed from $\left(4^{\prime \prime}\right),(19)$ and (20) assuming that job creation costs are given by $C^{i}\left(J^{i}\right)=g^{i}\left(J^{i}\right)^{\gamma}$ for $i=1,2$. 


\section{Table 2. Outcomes Under Isoelastic Cost of Job Creation}

100 Job Types and 100 Workers

Leisure Value $(\mathrm{z})=100, \quad \gamma=2 \quad \alpha=.5$

\begin{tabular}{|c|c|c|c|c|c|c|c|}
\hline Regime & $\begin{array}{l}\text { Workers' } \\
\text { Surplus }\end{array}$ & $\begin{array}{l}\text { Firms' } \\
\text { Surplus }\end{array}$ & $\begin{array}{l}\text { Net Per } \\
\text { Capita } \\
\text { Income }\end{array}$ & $\begin{array}{l}\text { Unemp. } \\
\text { Rate }\end{array}$ & $\begin{array}{l}\text { Average } \\
\text { Labor } \\
\text { Prod. }\end{array}$ & $\begin{array}{l}\text { Mean } \\
\text { Wage }\end{array}$ & $\begin{array}{l}\text { St. Dev. } \\
\text { Log Wage }\end{array}$ \\
\hline $\begin{array}{l}\text { Decentralized } \\
\text { Equil. }(\beta=.4)\end{array}$ & 10404 & 1492 & 118.96 & 0.0 & 126.8 & 110.7 & .35 \\
\hline $\begin{array}{l}\text { Decentralized } \\
\text { Equil. }(\beta=.5)\end{array}$ & 10475 & 1437 & 119.12 & 5.0 & 126.8 & 113.4 & .43 \\
\hline $\begin{array}{l}\text { Decentralized } \\
\text { Equil. }(\beta=.6)\end{array}$ & 10529 & 1364 & 118.93 & 12.2 & 126.8 & 116.1 & .51 \\
\hline $\begin{array}{l}\text { Efficient Wage } \\
\text { Structure }\end{array}$ & 11155 & 811 & 119.66 & 29.9 & 133.4 & 116.7 & 0.0 \\
\hline
\end{tabular}

Notes:

(i) The job creation cost coefficients are set to achieve a uniform distribution of job types in the decentralized equilibria.

(ii) The search efficiency parameter is set to deliver a five percent unemployment rate in the decentralized equilibrium with Nash bargaining $(\beta=.5)$.

(iii) The lower bound of the job productivity distribution is set to $110 \%$ of workers' reservation value. The upper bound is set so that the standard deviation of log wages equals .43 in the decentralized equilibrium with Nash bargaining $(\beta=.5)$.

(iv) See Figure 1 for a display of the job quality distribution in the various regimes. 
Table 3. Outcomes Under Three Alternative Regimes: Decentralized Bargaining, Optimal Tax Structure, and Efficient Wage Structure

\begin{tabular}{lllllllllllll}
\multicolumn{1}{c}{} & \multicolumn{1}{c}{ Parameter Settings } & \multicolumn{4}{c}{ Avg. Prod. } & \multicolumn{2}{l}{ Per Capita Income } \\
& $\alpha$ & $\gamma$ & $g^{2} / g^{1}$ & $z$ & $y^{1}$ & $y^{2}$ & $\beta$ & Decent.Eff. & \multicolumn{2}{c}{ Decent.Eff. } \\
$(1)$ & .5 & 2.0 & 1.0 & 50 & 80 & 100 & .25 & 92.5 & 95.9 & 73.86 & 75.55 \\
$(2)$ & .5 & 2.0 & 1.0 & 50 & 80 & 100 & .50 & 92.5 & 95.9 & 74.96 & 75.55 \\
$(3)$ & .5 & 2.0 & 1.0 & 50 & 80 & 100 & .75 & 92.5 & 95.9 & 73.11 & 75.55 \\
$(4)$ & .5 & 2.0 & 1.0 & 50 & 75 & 100 & .50 & 91.7 & 100.0 & 73.95 & 74.23 \\
$(5)$ & .3 & 2.0 & 1.0 & 50 & 90 & 100 & .50 & 95.6 & 97.1 & 75.91 & 77.18 \\
$(6)$ & .7 & 2.0 & 1.0 & 50 & 70 & 100 & .50 & 91.4 & 95.5 & 74.26 & 75.72 \\
$(7)$ & .5 & 2.0 & 2.0 & 50 & 90 & 100 & .50 & 93.8 & 94.4 & 74.03 & 74.13
\end{tabular}

Wage, Job Distribution, and Tax Outcomes

Decent. Bargaining Optimal Tax/Subsidy Policy Efficient Wage Structure $J^{1} / J \quad w^{1} \quad w^{2} \quad J^{1 / J} \quad T^{1} \quad T^{2} \quad w^{1} \quad w^{2} \quad J^{1 / J} \quad w^{1}=w^{2}$

$\begin{array}{lllllllllll}\text { (1) } & .37 & 57.5 & 62.5 & .21 & 20.6 & 13.9 & 52.4 & 59.0 & .21 & 72.9\end{array}$

$\begin{array}{lllllllllll}(2) & .37 & 65.0 & 75.0 & .21 & 15.9 & -4.1 & 57.1 & 77.1 & .21 & 72.9\end{array}$

$\begin{array}{lllllllllll}\text { (3) } & .37 & 72.5 & 87.5 & .21 & 1.7 & -58.3 & 71.2 & 131.2 & .21 & 72.9\end{array}$

$\begin{array}{lllllllllll}\text { (4) } & .33 & 62.5 & 75.0 & .00 & 25.0 & 0.0 & 50.0 & 75.0 & .00 & 75.0\end{array}$

$\begin{array}{lllllllllll}(5) & .44 & 70.0 & 75.0 & .29 & 25.9 & 15.9 & 57.1 & 67.1 & .29 & 83.0\end{array}$

$\begin{array}{lllllllllll}\text { (6) } & .29 & 60.0 & 75.0 & .15 & 7.3 & -22.7 & 56.3 & 86.3 & .29 & 63.7\end{array}$

$\begin{array}{lllllllllll}(7) & .62 & 70.0 & 75.0 & .56 & 4.4 & -5.6 & 67.8 & 77.8 & .56 & 72.2\end{array}$

Notes:

(i) The decentralized outcome is the solution to the model in section II with two job types. It solves equations $\left(3^{\prime}\right),(13 . a)$ and (13.b). The optimal tax/subsidy outcome solves the same model with a tax/subsidy policy that produces an efficient distribution of job types. It solves equations (12.a), (12.b), (22), and (23). The efficient wage structure outcome solves (12.a), (12.b) and (19).

(ii) Table entries are computed assuming that $C^{i}\left(J^{i}\right)=g^{i}\left(J^{i}\right)^{\gamma}$ for $i=1,2$. In solving for per capita income, additional parameters are scaled as follows: $L=10, a=.7$ and $g^{1}=1$. 
(iii) Per capita income is calculated net of job creation costs.

(iv) The invariance of the job distribution with respect to $\beta$ in the decentralized equilibrium is a special implication of the functional form chosen for job creation costs. 


\section{Table 4. The Effects of Centralized Wage Determination}

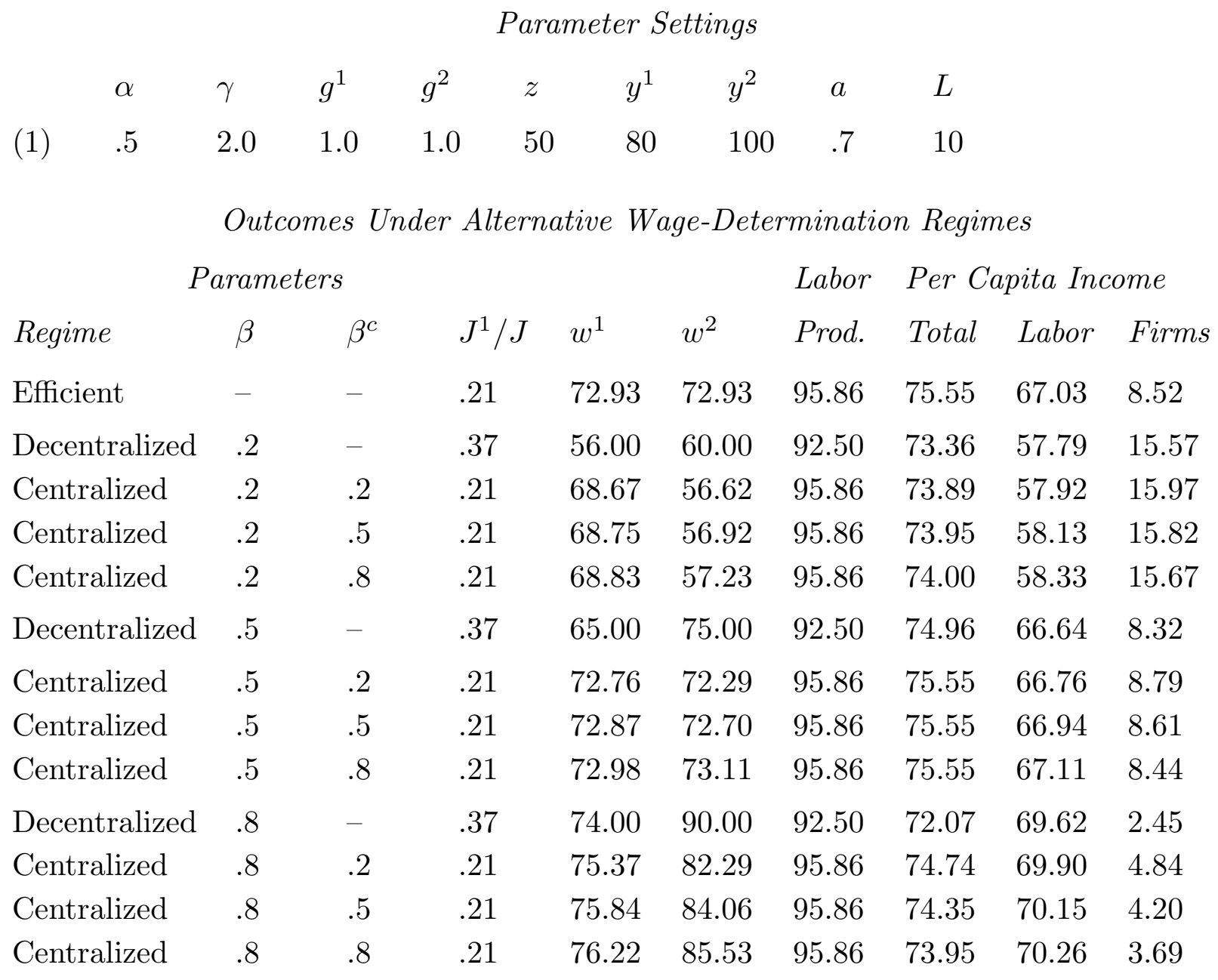

Notes:

(i) Wages obey (20) and quantities solve (12.a) and (12.b) in the efficient wage-structure regime. Wages obey $\left(3^{\prime}\right)$ and quantities solve (13.a) and (13.b) in the decentralized bargaining regime. Wages solve the constrained optimization problem (33)-(34) in the centralized bargaining regime, and quantities then follow from (34). 


\section{Figure 1 \\ The Quality Distribution of Jobs: \\ Decentralized Equilibrium and Efficient Outcomes}

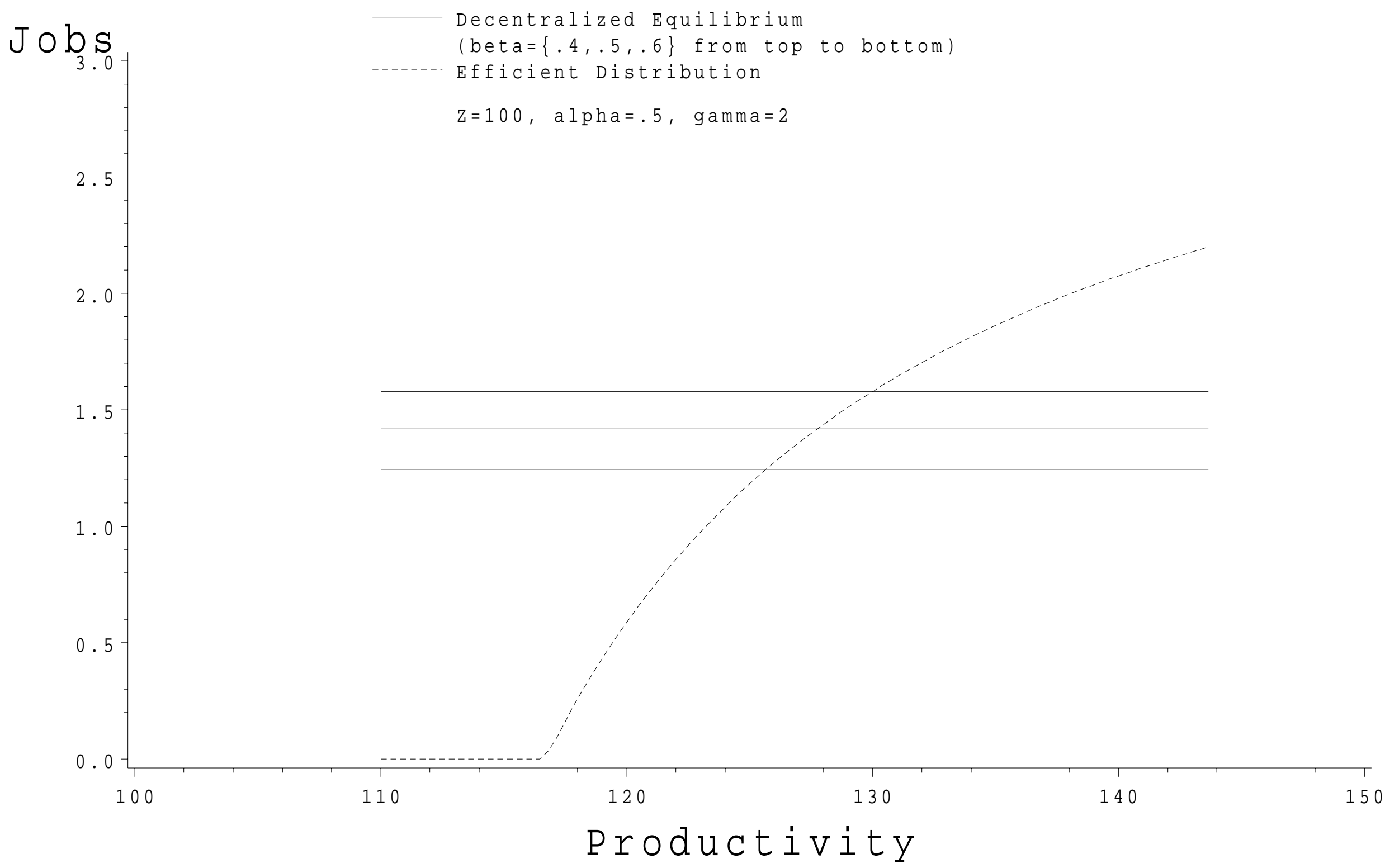

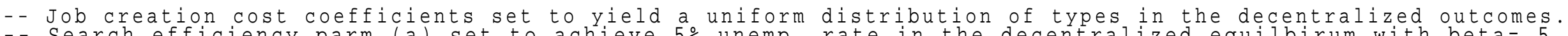

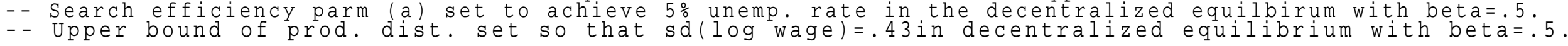

